\title{
Temporal Clustering of Antiglomerular Basement Membrane Disease in COVID-19 Pandemic: A Case Series
}

\section{Rakesh Sebastian \\ Jegan Arunachalam \\ Manorajan Rajendran}

Department of Nephrology, Government Rajaji Hospital, Madurai Medical College, Madurai, Tamil Nadu, India

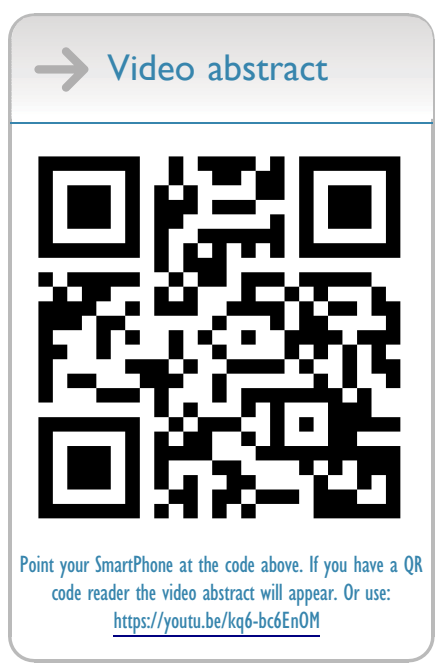

Correspondence: Jegan Arunachalam Department of Nephrology, Government Rajaji Hospital, Madurai Medical College, Madurai, Tamil Nadu, India

Tel +9l 9994373260

Email jeganmddm@gmail.com

\begin{abstract}
Anti-glomerular basement membrane disease (anti-GBM) affects mainly kidneys and lungs. It requires aggressive immunosuppressive treatment. Since the emergence of the severe acute respiratory syndrome coronavirus-2 (SARS-CoV-2), there has been an increased number of new cases of anti-GBM disease presenting as rapidly progressive glomerulonephritis (RPGN). The causal relationship is still speculative. We report a case series of four patients affected with COVID-19 infection presenting later with anti-GBM disease.
\end{abstract}

Keywords: anti glomerular basement membrane disease, COVID-19, case series, plasmapheresis

\section{Plain Language Summary}

Anti-GBM disease is a rare autoimmune disease usually presenting as rapidly progressive glomerulonephritis. There are various associated triggering factors for the disease. After the COVID-19 disease became rampant throughout the world, there have been case reports suggesting SARS-CoV-2 infection as a possible triggering event for the development of antiGBM disease. We report a case series of four patients infected with COVID-19 and presenting later with anti-GBM disease.

\section{Introduction}

Anti-glomerular basement membrane (anti-GBM) disease is an autoimmune disease leading to rapidly progressive glomerulonephritis (RPGN). Pathogenesis of the anti-GBM disease is by developing autoantibodies targeting cryptic antigen expressed in the basement membranes of the kidney and lungs. The widespread glomerular crescent formation, presenting with rapidly progressive GN and alveolar haemorrhage, are standard features. ${ }^{1}$ Crescent formation is the hallmark of the antiGBM disease. Large study series suggest that $95 \%$ of patients will have crescent formation on kidney biopsy. Nearly in $80 \%$ of the patients, more than $50 \%$ of glomeruli will be involved. These crescents will typically be of uniform age (same stage of development). In addition, the proportion of crescents in the biopsy sample correlates with the degree of renal failure at presentation. ${ }^{2}$ The recent evidence of spatial and temporal clustering of cases suggests that various environmental factors, including infection, may trigger the disease in susceptible individuals. ${ }^{3}$

There has been a recent increase in the incidence of anti-GBM disease since the pandemic of novel SARS-CoV2 infection, suggesting a possible association 
between the two. ${ }^{4}$ Severe endothelial injury and disturbed endothelial cell membranes are features of COVID-19 infection, maybe an initiating event in exposing the cryptic basement membrane antigen. However, the causal association is still speculative. We report a case series of four patients affected by COVID-19 infection presenting later with anti-GBM disease.

\section{Materials and Methods}

The study was done in Madurai Medical College from September 2020 to March 2021. Four patients presented as new-onset rapidly progressive glomerulonephritis, biopsy-proven anti-GBM disease with either COVID RTPCR or COVID IgG or IgM antibody positive were enrolled for the study. Their clinical features, anti-GBM titer, renal parameters, kidney biopsy pattern, progression to end-stage kidney disease, and response to treatment were studied (Table 1). Consent was obtained from all four patients to collect and publish the data. The institutional ethical committee approval is not mandatory for publishing the case details. However, we obtained the clearance for publishing the data.

\section{Case I}

A 36-year-old woman, non-smoker with a history of sinusitis, fever, headache 4 weeks back presented to the outpatient department with complaints of lethargy, hematuria, and vomiting. The patient did not have any previous history of renal failure or other comorbid conditions. His laboratory parameters were hemoglobulin of $7.8 \mathrm{~g} / \mathrm{dl}$, total leukocyte count of $6800 \mathrm{~mm}^{3}$, and platelet count of $2,30,000 / \mathrm{mm}^{3}$. Her serum creatinine was $3.4 \mathrm{mg} / \mathrm{dl}$ on blood investigations. Serum complement levels C3 and C4 were within normal limits. Both P-ANCA and C-ANCA were negative. Anti-GBM titre was $287 \mathrm{IU} /$ $\mathrm{mL}$. COVID-19 RT PCR and IgG antibody were negative. The patient was tested positive for COVID-19 IgM antibody. Her CT thorax showed 5\% lung involvement, suggestive of COVID-19. Renal biopsy on light microscopy showed cellular crescents (Figures 1 and 2), no interstitial fibrosis or tubular atrophy, with immunofluorescence microscopy showing linear IgG deposition in the GBM (Figure 3). The patient was treated with $500 \mathrm{mg}$ methylprednisolone intravenously for 3 days, followed by oral prednisolone, hemodialysis, plasmapheresis, and oral cyclophosphamide at $2 \mathrm{mg} / \mathrm{kg}$ dose. The patient was on regular outpatient follow-up, and her last serum creatinine was $3.8 \mathrm{mg} / \mathrm{dl}$.

\section{Case 2}

An 18-year-old man, a non-smoker with a history of fever and sore throat 8 weeks back, presented to the outpatient department with complaints of headache, accelerated systemic Hypertension (BP- 200/120 mmHg), and renal failure.

The patient did not have any history of renal failure or other comorbid conditions. His blood investigations revealed $\mathrm{Hb}$ of $11 \mathrm{~g} / \mathrm{dl}$, total leukocyte count of $7600 \mathrm{~mm}^{3}$, and a platelet count of $1,25,000 / \mathrm{mm}^{3}$. His serum creatinine was $7 \mathrm{mg} / \mathrm{dl}$. The patient tested positive for P-ANCA, and serum $\mathrm{C} 3$ and $\mathrm{C} 4$ were within normal limits. Anti-GBM titer was $567 \mathrm{IU} / \mathrm{mL}$. COVID-19 RTPCR and IgG antibody were negative. The patient was tested positive for COVID-19 IgM antibody. CT thorax showed 5\% lung involvement suggestive of COVID-19. Her renal biopsy on light microscopy showed cellular and fibro cellular crescents, and immunofluorescence showed linear IgG staining in the GBM. There was no interstitial fibrosis or tubular atrophy. The patient was treated with $500 \mathrm{mg}$ methylprednisolone intravenously for 3 days, followed by oral prednisolone, hemodialysis, plasmapheresis, and oral cyclophosphamide at $2 \mathrm{mg} / \mathrm{kg}$ dose. The patient was on regular follow-up, and his last serum creatinine was $5.0 \mathrm{mg} / \mathrm{dl}$.

\section{Case 3}

A 53-year-old male smoker with a history of fever and cough 6 weeks back presented to the emergency room with volume overload and anuria. The patient did not have any history of renal failure or other comorbid conditions. His blood investigations revealed hemoglobulin of $8 \mathrm{~g} / \mathrm{dl}$, total leukocyte count of $12,000 / \mathrm{mm}^{3}$, platelet count of $1,50,000 / \mathrm{mm}^{3}$. His serum creatinine was $12 \mathrm{mg} / \mathrm{dl}$. The patient was tested negative for P-ANCA and C-ANCA, and his $\mathrm{C} 3$ and $\mathrm{C} 4$ were within normal limits. Anti-GBM titer was $323 \mathrm{IU} / \mathrm{mL}$. COVID-19 RTPCR was negative, but the patient tested positive for both IgM and IgG COVID-19 antibodies. CT thorax showed 5\% lung involvement suggestive of COVID-19. Renal biopsy on light microscopy showed cellular and circumferential fibrocellular crescents, and on immunofluorescence, linear $\operatorname{IgG}$ staining in the GBM was seen. Interstitial fibrosis and tubular atrophy were around $40 \%$. The patient was treated with $500 \mathrm{mg}$ methylprednisolone intravenously for 3 days followed by oral prednisolone, hemodialysis, plasmapheresis, oral cyclophosphamide at a $2 \mathrm{mg} / \mathrm{kg}$ dose. The patient rapidly 
Table I Cases of Anti-Glomerular Basement Membrane Disease Post SARS-CoV2 Infection

\begin{tabular}{|c|c|c|c|c|}
\hline & Case I & Case 2 & Case 3 & Case 4 \\
\hline Age/Gender & $36 / F$ & I8/M & $52 / M$ & $32 / F$ \\
\hline Comorbidity & Nil & Nil & Hypertensive & Nil \\
\hline Smoking status & Nil & Nil & Smoker & Nil \\
\hline Clinical presentation & $\begin{array}{l}\text { Lethargy, hematuria, } \\
\text { vomiting }\end{array}$ & $\begin{array}{l}\text { Headache, accelerated } \\
\text { hypertension }\end{array}$ & $\begin{array}{l}\text { Volume overload, } \\
\text { vomiting }\end{array}$ & $\begin{array}{l}\text { Volume overload, fever, } \\
\text { hematuria, oliguria }\end{array}$ \\
\hline $\begin{array}{l}\text { Preceding clinical } \\
\text { SARS-CoV2 infection }\end{array}$ & Present - mild & Present - moderate & Present - mild & Present - moderate \\
\hline Prodrome duration & 4 weeks & 8 weeks & 6 weeks & 4 weeks \\
\hline Alveolar hemorrhage & Absent & Absent & Absent & Absent \\
\hline Hemoglobin & $7.8 \mathrm{~g} / \mathrm{dl}$ & $\mathrm{l} \mid \mathrm{g} / \mathrm{dl}$ & $8 g / d l$ & $8.2 \mathrm{~g} / \mathrm{dl}$ \\
\hline Renal syndrome & AKI & AKI-RRT & AKI-RRT & AKI-RRT \\
\hline Platelets & $2,30,000 / \mathrm{mm}^{3}$ & $\mathrm{I}, 25,000 / \mathrm{mm}^{3}$ & $1,50,000 / \mathrm{mm}^{3}$ & $\mathrm{I}, 12,000 / \mathrm{mm}^{3}$ \\
\hline Serum creatine & $3.4 \mathrm{mg} / \mathrm{dl}$ & $7 \mathrm{mg} / \mathrm{dl}$ & $12 \mathrm{mg} / \mathrm{dl}$ & $16 \mathrm{mg} / \mathrm{dl}$ \\
\hline C-reactive protein & $0.7 \mathrm{mg} / \mathrm{L}$ & $15 \mathrm{mg} / \mathrm{L}$ & $4 \mathrm{mg} / \mathrm{L}$ & $65 \mathrm{mg} / \mathrm{L}$ \\
\hline $\begin{array}{l}\text { Anti-GBM titre (IU/ } \\
\mathrm{mL} ; \text { normal <6.9) }\end{array}$ & 287 & 567 & 323 & 386 \\
\hline ANCA & Negative & Positive (p-ANCA) & Negative & Negative \\
\hline Renal Biopsy & $\begin{array}{l}\text { Crescentric glomerular } \\
\text { Nephritis, no interstitial } \\
\text { fibrosis and tubular atrophy, } \\
\text { linear } \lg G \text { staining }\end{array}$ & $\begin{array}{l}\text { Cellular and fibrocellular } \\
\text { crescents, linear lgG } \\
\text { staining, no interstitial } \\
\text { fibrosis and tubular atrophy }\end{array}$ & $\begin{array}{l}\text { Circumferential } \\
\text { fibrocellular and cellular } \\
\text { crescents, linear lgG } \\
\text { staining, IFTA } 40 \%\end{array}$ & $\begin{array}{l}\text { Cellular and fibrocellular } \\
\text { crescents, linear lgG } \\
\text { staining, no interstitial } \\
\text { fibrosis and tubular atrophy }\end{array}$ \\
\hline \multicolumn{5}{|l|}{ SARS-CoV2 } \\
\hline I. RTPCR & I. Negative & I. Negative & I. Negative & I. Negative \\
\hline 2. IgG antibody & 2. Negative & 2. Negative & 2. Positive & 2. Negative \\
\hline 3. IgM antibody & 3. Positive & 3 .Positive & 3. Positive & 3. Positive \\
\hline Treatment & Plasma exchange, steroids & $\begin{array}{l}\text { Plasma exchange, steroids, } \\
\text { cyclophosphamide }\end{array}$ & $\begin{array}{l}\text { Plasma exchange, steroids, } \\
\text { cyclophosphamide }\end{array}$ & $\begin{array}{l}\text { Plasma exchange, steroids, } \\
\text { cyclophosphamide }\end{array}$ \\
\hline Outcome & Outpatient follow-up & Outpatient follow-up & On weekly twice RRT & Inpatient RRT \\
\hline Last creatinine & $3.8 \mathrm{mg} / \mathrm{dl}$ & $5 \mathrm{mg} / \mathrm{dl}$ & $5.8 \mathrm{mg} / \mathrm{dl}$ & $6.8 \mathrm{mg} / \mathrm{dl}$ \\
\hline
\end{tabular}

progressed to ESRD, and he is on weekly twice hemodialysis now. His last serum creatinine was $5.8 \mathrm{mg} / \mathrm{dl}$.

\section{Case 4}

A 32-year-old female non-smoker with a history of upper respiratory infection 6 weeks back presented to the emergency room with fever, hematuria, and oliguria. The patient did not have any history of renal failure or other comorbid conditions. Her blood investigations revealed hemoglobin of $8.2 \mathrm{~g} / \mathrm{dl}$, total leukocyte count of $6200 \mathrm{~mm}^{3}$, and platelet count of $1,12,000 / \mathrm{mm}^{3}$. Her serum creatinine was found to be $16 \mathrm{mg} / \mathrm{dl}$ with severe renal failure. Serum complement levels were within normal limits. The patient was also tested negative for P-ANCA and C-ANCA. Her anti-GBM titre was $386 \mathrm{IU} /$ mL. COVID-19 RTPCR and IgG antibody were negative, 


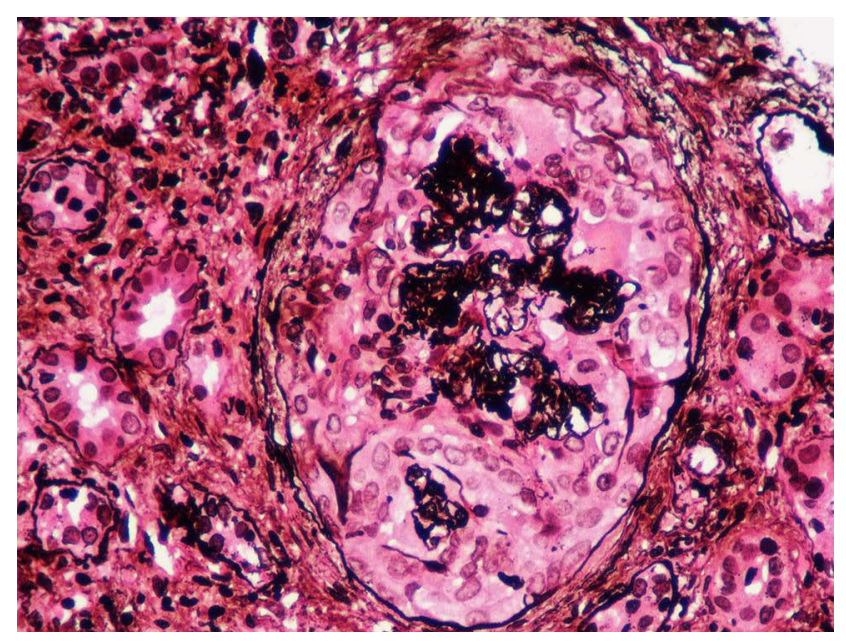

Figure I Silver staining delineating basement membrane and showing cellular crescent.

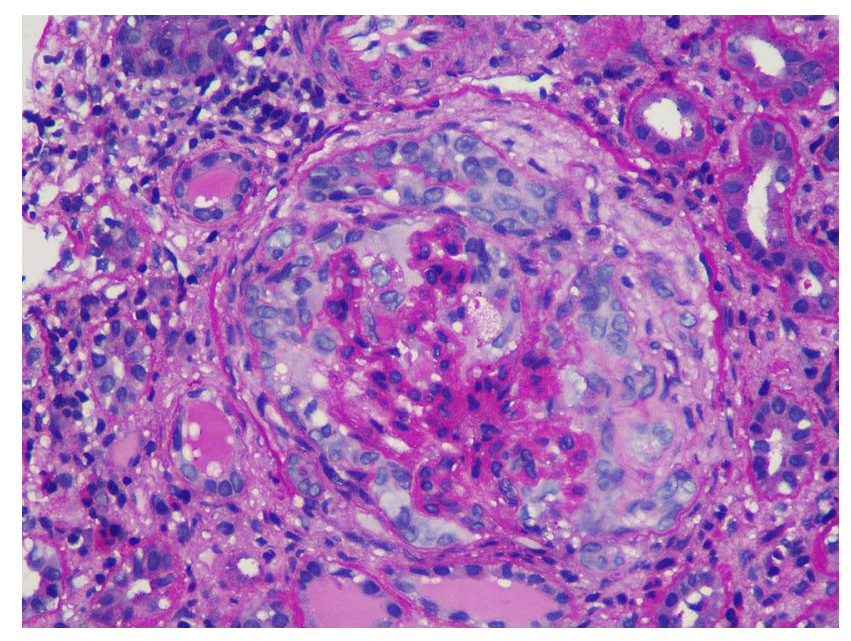

Figure 2 PAS staining showing cellular crescents compressing glomerular tuft.

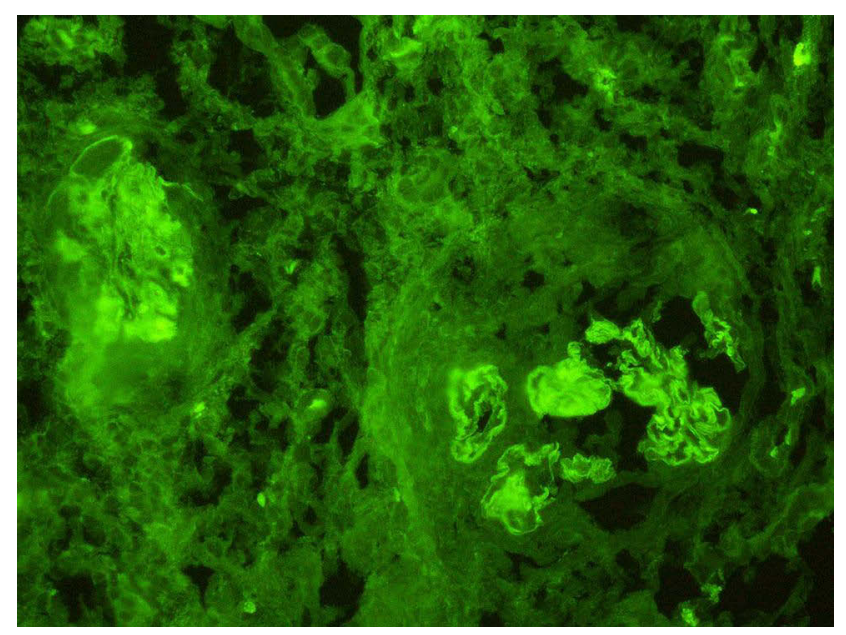

Figure 3 Direct immunofluorescence showing IgG deposition over glomerular basement membrane. but the patient tested positive for the IgM COVID-19 antibody. CT thorax showed $8 \%$ lung involvement. Renal biopsy on light microscopy showed cellular and fibro cellular crescents and immunofluorescence showed linear IgG staining in the GBM. There was no interstitial fibrosis or tubular atrophy. The patient was treated with $500 \mathrm{mg}$ methylprednisolone intravenously for 3 days, followed by oral prednisolone, hemodialysis, plasmapheresis, and oral cyclophosphamide at a $2 \mathrm{mg} / \mathrm{kg}$ dose. The patient is on inpatient weekly twice hemodialysis now. Her last creatinine was $6.8 \mathrm{mg} / \mathrm{dl}$.

\section{Discussion}

Anti-GBM disease is a rare autoimmune small-vessel vasculitis. Environmental factors such as infection may trigger the disease in susceptible individuals. ${ }^{1}$ A recent surge in the number of anti-GBM cases reported by Prendecki et al in the UK showed a fivefold increase in the number of antiGBM cases from December 2019 to April 2020. ${ }^{4}$ Our case series supports the pathogenic association between COVID-19 and anti-GBM disease. The incidence of antiGBM disease in India is $5.1 \%$ among all crescentic glomerulonephritis with a male-to-female ratio of $5: 6$. The male-to-female ratio in our case series is 1:1. Most patients were affected in their third to the fifth decade. ${ }^{5}$ It is observed from more extensive case series that anti-GBM has bimodal age distribution with peak incidence during the third decade and presentation with pulmonary renal disease and in the sixth and seventh decades, where presentation with isolated kidney involvement is more common. ${ }^{6}$ There are no case reports of anti-GBM disease associated with COVID-19 in India. Most of the cases of anti-GBM diseases reported by Prendecki et $\mathrm{al}^{4}$ were followed by mild-to-moderate prodromal illness. The average period between prodromal illness and renal symptoms was around 6 weeks, similar to our case series. The prodromal symptoms in our case series were mild to moderate. None of them were tested positive for COVID-19 RTPCR but tested positive for either COVID-19 IgG or IgM antibodies. Antibody positivity, particularly IgM, indicates COVID-19 infection in the recent past. About $20-30 \%$ of the anti-GBM patients are also associated with ANCA positivity, and the majority are anti-MPO positive. ${ }^{7}$ In our case series, one patient tested positive for P-ANCA. All patients had elevated anti-GBM titers. The severity of renal failure was proportional to the level of anti-GBM titer. One patient only had cellular crescents in our case series, and all the remaining three had both cellular and fibrocellular 
crescents. Recurrence of anti-GBM disease post-COVID -19 , a 30-year-old woman with hemoptysis and rapidly progressive renal failure has also been reported. ${ }^{8}$ None of the anti-GBM disease cases reported by Prendecki et al had hemoptysis, which is similar to our case series. Spatial and temporal variations and their association with an increase in the incidence of anti-GBM disease show environmental factors may play a role in causation. ${ }^{9}$ Severe endothelial injury and disturbed endothelial cell membranes are features of COVID-19 infection. ${ }^{10}$ Endothelial injury may expose the basement membrane. Alpha 3 chain of type four collagen ( $\mathrm{NC1}$ domain) is present in the glomerular and pulmonary basement membranes ${ }^{1,9,10}$ Endothelial injury may release NC1 into circulation. Localized inflammation induced by the endothelial injury may increase the capillary permeability and potentially disrupt the quaternary structure of the alveolar basement membrane exposing the sequestrated antigens and allowing access to the pathogenic autoantibodies. ${ }^{11}$ Two autoantibodies (B cell) epitopes within the autoantigen have been identified, designated $\mathrm{EA}$ and $\mathrm{EB}$, which in native GBM are sequestrated within the quaternary structure of the $\mathrm{NC} 1$ domain of type 4 collagen. ${ }^{12}$ Circulating plasma cells may react to the $\mathrm{NC} 1$ domain antigen to produce autoreactive $\mathrm{B}$ and $\mathrm{T}$ cells, eventually leading to the pulmonary-renal syndrome. Proteinuria and hematuria are reported in many COVID-19 patients indicating glomerular injury during the infection. The casual relation between COVID-19 infection anti-GBM disease has not been clearly established until now.

All of our patients received treatment with cyclophosphamide, steroids, plasmapheresis. All of them have clinically improved. Two patients were on outpatient follow-up, and two became hemodialysis dependent.

\section{Limitation}

Our study is a case series. So causal association of COVID-19 infection triggering autoimmune response resulting in anti-GBM disease cannot be concluded definitely. However, this case series can be hypothesisgenerating, and we need further research to be conducted in the future to establish the causal relationship between COVID-19 infection and anti-GBM disease.

\section{Conclusion}

Our case report suggests a possible pathogenic association of COVID-19 infection triggering an autoimmune response leading to anti-GBM causing a rapidly progressive form of crescentic glomerulonephritis.

\section{Abbrevations}

GBM, glomerular basement membrane; SARS-CoV2, severe acute respiratory syndrome coronavirus 2; RPGN, rapidly progressive glomerular nephritis; ANCA, anti-neutrophilic cytoplasmic antibody; ANTI-MPO, anti-myeloperoxidase antibody; NC1 domain, non-collagenous type 1 domain.

\section{Statement of Ethics}

The patients have given written informed consent to publish their cases (including publication of images) under a condition of anonymity. The research was conducted within the framework of the guidelines for human studies, and it was conducted ethically following the World Medical Association Declaration of Helsinki.

\section{Consent for Publication}

Informed written consent was obtained for publishing data and figures. The institutional ethical committee approval is not mandatory for publishing the case details. However, we obtained the clearance for publishing the data.

\section{Funding}

There is no funding to report.

\section{Disclosure}

The authors report no conflicts of interest for this work.

\section{References}

1. McAdoo S, Pusey C. Anti-glomerular basement membrane disease. Clin J Am Soc Nephrol. 2017;12(7):1162-1172. doi:10.2215/CJN.013 80217

2. Jennette JC. Rapidly progressive crescentic glomerulonephritis. Kidney Int. 2003;63(3):1164-1177. PMID: 12631105. doi:10.1046/ j.1523-1755.2003.00843.x

3. Canney M, O'Hara PV, McEvoy CM, Medani S. Spatial and temporal clustering of anti-glomerular basement membrane disease. Clin J Am Soc Nephrol. 2016;11(8):1392-1399. PMID: 27401523; PMCID: PMC4974897. doi:10.2215/CJN.13591215

4. Prendecki M, Clarke C, Cairns T, et al. Anti-glomerular basement membrane disease during the COVID-19 pandemic. Kidney Int. 2020;98(3):780-781. PMID: 32599088; PMCID: PMC7318989. doi:10.1016/j.kint.2020.06.009

5. Prabhakar D, Rathi M, Nada R, et al. Anti-glomerular basement membrane disease: case series from a tertiary center in North India. Indian J Nephrol. 2017;27(2):108-112. PMID: 28356661; PMCID: PMC5358149. doi:10.4103/0971-4065.171227

6. Savage CO, Pusey CD, Bowman C, Rees AJ, Lockwood CM. Antiglomerular basement membrane antibody-mediated disease in the British Isles 1980-1984. Br Med J. 1986;292(6516):301-304. PMID: 3080145; PMCID: PMC1339276. doi:10.1136/bmj.292.65 16.301 
7. Levy JB, Hammad T, Coulthart A, Dougan T, Pusey CD. Clinical features and outcome of patients with both ANCA and anti-GBM antibodies. Kidney Int. 2004;66(4):1535-1540. PMID: 15458448. doi:10.1111/j.1523-1755.2004.00917.x

8. Winkler A, Zitt E, Sprenger-Mähr H, et al. SARS-CoV-2 infection and recurrence of anti-glomerular basement disease: a case report. BMC Nephrol. 2021;22(75). doi:10.1186/s12882-021-02275-4

9. McAdoo S, Pusey C. Clustering of anti-GBM disease: clues to an environmental trigger? Clin $J$ Am Soc Nephrol. 2016;11 (8):1324-1326. doi:10.2215/CJN.05580516

10. Segelmark M, Hellmark T. Autoimmune kidney diseases. Autoimmun Rev. 2010;9(5):A366-71. PMID: 19906361. doi:10.1016/j.autrev.20 09.11 .007
11. Pei G, Zhang Z, Peng J, et al. Renal involvement and early prognosis in patients with COVID-19 Pneumonia. J Am Soc Nephrol. 2020;31 (6):1157-1165. PMID: 32345702; PMCID: PMC7269350. doi:10. 1681/ASN.2020030276

12. Netzer KO, Leinonen A, Boutaud A, et al. The Goodpasture autoantigen. Mapping the major conformational epitope(s) of alpha3 (IV) collagen to residues $17-31$ and $127-141$ of the NC1 domain. $J$ Biol Chem. 1999;274(16):11267-11274. PMID: 10196215. doi:10.1074/ jbc.274.16.11267

\section{Publish your work in this journal}

The International Journal of Nephrology and Renovascular Disease is an international, peer-reviewed open-access journal focusing on the pathophysiology of the kidney and vascular supply. Epidemiology, screening, diagnosis, and treatment interventions are covered as well as basic

science, biochemical and immunological studies. The manuscript management system is completely online and includes a very quick and fair peer-review system, which is all easy to use. Visit http://www.dovepress.com/testimonials.php to read real quotes from published authors. 